\title{
Formulation and validation of a two-dimensional steady-state model of desiccant wheels
}

Bellemo, Lorenzo; Elmegaard, Brian; Kærn, Martin R.; Markussen, Wiebke B.; Reinholdt, Lars O.

\section{Published in:}

Science and Technology for the Built Environment

Link to article, DOI:

10.1080/10789669.2014.965607

Publication date:

2015

Document Version

Peer reviewed version

Link back to DTU Orbit

Citation (APA):

Bellemo, L., Elmegaard, B., Kærn, M. R., Markussen, W. B., \& Reinholdt, L. O. (2015). Formulation and validation of a two-dimensional steady-state model of desiccant wheels. Science and Technology for the Built Environment, 21(3), 300-311. https://doi.org/10.1080/10789669.2014.965607

\section{General rights}

Copyright and moral rights for the publications made accessible in the public portal are retained by the authors and/or other copyright owners and it is a condition of accessing publications that users recognise and abide by the legal requirements associated with these rights.

- Users may download and print one copy of any publication from the public portal for the purpose of private study or research.

- You may not further distribute the material or use it for any profit-making activity or commercial gain

- You may freely distribute the URL identifying the publication in the public portal 


\section{Formulation and validation of a two-dimensional steady state model of desiccant wheels}

Desiccant wheels are rotary desiccant dehumidifiers used in air conditioning and drying applications. The modeling of simultaneous heat and mass transfer in these components is crucial for estimating their performances, as well as for simulating and optimizing their implementation in complete systems. A steady state two-dimensional model is formulated and implemented aiming to obtain good accuracy and short computational times with the purpose of inclusion in complete system models. The model includes mass and energy balances and correlations for heat and mass transfer based on empirical relations from the scientific literature. Convective heat and mass transfer coefficients are computed locally accounting for the entrance length effects. Mass diffusion inside the desiccant material is neglected. Comparison with experimental data from the literature shows that the model reproduces the physical behavior of desiccant wheels satisfactorily, as the deviation between the computed results and available data is always within 12\%. The simulation time is as low as 3 seconds for a model with 200 control volumes. It is found that for the applied case, the model provides accurate results for the overall flow using an equiangular control volume discretization with 200 control volumes and no axial discretization. More computationally expensive configurations with axial discretization give more accurate results and information on local flow and desiccant conditions inside the wheel.

\section{Introduction}

Desiccant Wheels (DWs) are mainly used in drying applications as well as in desiccant cooling systems for air conditioning (La et al., 2010). DWs are constituted by identical channels aligned lengthwise and distributed into concentric layers. This structure is obtained by means of a support material onto which the desiccant is attached. The wheel is divided into two sections, namely process and regeneration sections, and purge sections can be added, if required. The process airstream, to be dehumidified, flows through the process section, while the regeneration airstream flows through the regeneration section from the opposite 
direction. A small electric motor makes the wheel rotate, i.e. all channels move continuously between the two sections. A sketch of the considered DW configuration is reported in Fig. 1, including a detailed front view of a sinusoidal channel. In Fig. 1 the wheel is illustrated with the same size of the process and regeneration sides. This is defined by the process side and regeneration side angles, which here both are $180^{\circ}$.

The dehumidification mechanism taking place in the process section is adsorption. Water vapor molecules migrate from the humid air to the desiccant and diffuse inside the desiccant capillaries, where they bind to the desiccant surface. The adsorption process is exothermic and thus rejects heat during the process, resulting in an increased temperature of the dried air. In the regeneration section the opposite phenomenon, termed desorption, takes place by circulating a hot airstream with low relative humidity. Adsorption and desorption are driven by the water vapor partial pressure difference between the bulk of the humid air and the layer of humid air at the desiccant surface, which at low water vapor concentrations can be calculated as the humidity ratio difference between the two locations (Mills, 2001). The wheel rotation allows for a continuous dehumidification process that reaches a steady state operation at constant rotational speed and air inlet conditions.

Several DW models have been published in the last decades. Disregarding empirical models, two different approaches for modeling the coupled heat and mass transfer processes in DWs can be identified.

The most common approach considers a single channel in the DW, i.e. a control mass of desiccant with a varying inlet airflow according to the angular position. The desiccant control mass experiences varying conditions due to the rotation of the wheel. The corresponding system of partial differential equations is discretized in space and integrated over time. It will eventually reach a steady state operating condition. The conditions at different DW circumferential locations correspond to the conditions at different time steps for the control mass of one channel. A review of models based on this approach is presented in $(\mathrm{Ge}$ et al., 2008).

Another approach consists of dividing the entire DW volume into Control Volumes (CVs). Flows of both humid air and desiccant including adsorbed water enter and exit each CV. The corresponding system of partial differential equations is discretized, however, in space solely. It results in a system of algebraic equations expressing energy and mass balances and heat and mass transfer. This approach reduces the 
computational effort required to solve the system, i.e. the DW steady state operation can be computed quickly, facilitating the simulation of more complex systems. Two previous 2D models based on this approach are reported in (Tsutsui, 2008) and (Harshe, 2005). These models use constant heat and mass transfer coefficients for the entire wheel, such that e.g. entrance effects cannot be captured. The effects caused by thermal and hydraulic development in the entrance length change the temperature levels and humidity contents and may lead to selecting different optimal operating conditions.

The model presented in this paper is based on the control volume approach. The wheel is discretized in two dimensions, and heat and mass transfer coefficients are found for each control volume based on local conditions including entrance effects. The goal is to obtain high accuracy and short computational time in order to facilitate whole system simulations of e.g. HVAC systems.

\section{Method}

\section{MODEL FORMULATION}

The numerical discretization approach is illustrated in Fig. 2 while the resulting 2D computational grid is shown in Fig. 3, i.e. $\mathrm{N}_{x} \mathrm{CVs}$ in the axial direction and $\mathrm{N}_{\vartheta} \mathrm{CVs}$ in the circumferential direction. The computed air and desiccant flow conditions to and from a CV as well as the conditions in the same CV center are constant in time during steady state operation.

The inputs to the model are:

- DW geometrical characteristics (diameter $D$, length $L$, regeneration angle $\alpha$ ).

- Channel geometrical characteristics ( $a, b, c$ in Fig. 1).

- DW rotational speed $N$.

- Desiccant material characteristics (density $\rho_{d}$, specific heat $c_{p, d}$, adsorption isotherm, integral heat of adsorption $\left.\Delta I_{a d s}\right)$.

- Air inlet conditions (temperatures $T$, humidity ratios $\omega$, mass flow rates $\dot{m}$ ).

\section{Assumptions}

The model is based on the following assumptions: 
- $\quad$ The wheel does not exchange heat with the surroundings.

- All channels are identical, i.e. airflows are homogeneously distributed among the channels at both sides.

- The desiccant material is uniformly distributed on the support structure.

- No heat and mass transfer take place between adjacent channels.

- The generated integral heat of wetting $\Delta I_{\text {wet }}$, i.e. the difference between the integral adsorption/desorption heat and the latent heat of condensation/vaporization (Sattler and Feindt, 1995), is exchanged between the desiccant and the water.

- Air velocity is much higher than the wheel rotational speed, i.e. air enters and exits the same CV.

- Air and desiccant are in equilibrium at the desiccant surface according to the adsorption isotherm.

- Heat conduction and mass diffusion are neglected in both the air and the desiccant.

- Variations of temperatures and humidity contents along the DW radial direction are neglected.

- Condensation of water vapor on the desiccant surface in the regeneration side is not considered.

As listed in the assumptions, heat conduction and mass diffusion in the desiccant are neglected. The dimensionless heat and mass transfer Biot numbers are useful indicators to measure the relative magnitude of the convective external resistance compared to the internal diffusive resistance within the desiccant itself. A Biot number much lower than 1 indicates that the gas-side resistance dominates over the solid-side resistance and vice versa. As reported in Goldsworthy and White (2014), common desiccant wheels have heat transfer Biot numbers much lower than 1 and mass transfer in the order of 10, i.e. both the solid-side and gas-side resistances are potentially important for mass transfer. As a consequence, the model might overestimate the moisture transfer in the wheel, resulting in lower supply air humidity ratios.

\section{Conservation laws}

Under these assumptions, the energy and mass balances are written for the generic (i,j) CV, considering mass and energy flows in accordance to Fig. 4.

The mass balances applied to the dry air, the dry solid matrix and the water (subscripts $a, m, w$ respectively) read: 


$$
\begin{gathered}
\dot{m}_{a, \text { in }}=\dot{m}_{a, \text { out }}=\dot{m}_{a} \\
\dot{m}_{m, \text { in }}=\dot{m}_{m, \text { out }}=\dot{m}_{m} \\
\dot{m}_{a}\left(\omega_{\text {in }(i, j)}-\omega_{\text {out }(i, j)}\right)+\dot{m}_{m}\left(W_{\text {in }(i, j)}-W_{\text {out }(i, j)}\right)=0
\end{gathered}
$$

where $W$ is the ratio of the mass of water adsorbed on the desiccant surface to the mass of dry desiccant. Due to the cyclic nature of the desiccant, an algebraic loop is introduced. This is resolved by only applying eq. (2) to all but one CV.

The energy balance applied to the humid air is expressed as:

$$
\dot{m}_{a}\left(I_{h a, i n(i, j)}-I_{h a, o u t(i, j)}\right)-\dot{Q}_{\text {sens }(i, j)}-\dot{Q}_{\text {lat }(i, j)}=0
$$

where $I$ is the air specific enthalpy, defined as:

$$
I_{h a}=c_{p, a} T_{a}+\omega\left(c_{p, v} T_{a}+\Delta I_{c o n, 0^{\circ} \mathrm{C}}\right)
$$

where $\Delta I_{c o n, 0^{\circ} \mathrm{C}}$ is the latent heat of water with reference temperature at $0^{\circ} \mathrm{C}$.

Heat transfer between the humid air and the solid matrix in Eq. (4) is essentially the sum of a sensible $\dot{Q}_{\text {sens }}$ and a latent $\dot{Q}_{\text {lat }}$ heat flow contribution and associated to convective heat and mass transfer, respectively:

$$
\begin{gathered}
\dot{Q}_{\text {sens }(i, j)}=h_{(i, j)} A\left(\bar{T}_{a(i, j)}-\bar{T}_{e q(i, j)}\right) \\
\dot{Q}_{l a t(i, j)}=\dot{m}_{w(i, j)} \Delta I_{c o n(i, j)}
\end{gathered}
$$

where the bar $\left(^{-}\right)$indicates averaged $\mathrm{CV}$ quantities. $A$ is the apparent desiccant area in contact with humid air and not the real area considering the surface of the capillaries in the desiccant material. The driving potential for the sensible heat exchanged is the temperature difference between the bulk of the air and the solid temperature. The subscript $e q$, which stands for equilibrium, is used for referring to the solid 
temperature, as air and solid are supposed to be in thermal equilibrium at their boundary and the solid temperature is the same throughout whole of its thickness. The latent heat exchanged by the air is directly proportional to the latent heat of condensation of water, and not affected by the integral heat of wetting, which is exchanged with the desiccant only. The integral heat of wetting accounts for the fact that water is bonded on the desiccant surface in the adsorbed state and not in the liquid state (Barlow, 1982).

The mass flow rate of water vapor adsorbed or desorbed in a CV is calculated as:

$$
\dot{m}_{w(i, j)}=\sigma_{(i, j)} A\left(\bar{\omega}_{(i, j)}-\bar{\omega}_{e q(i, j)}\right)=\dot{m}_{a}\left(\omega_{i n(i, j)}-\omega_{\text {out }(i, j)}\right)
$$

where $\sigma$ is the convective mass transfer coefficient in the air.

The desiccant adsorption isotherm couples the water content in the desiccant with the relative humidity of the adjacent air $\phi_{\text {eq }}$ by assuming they are in thermal equilibrium with each other. This allows computing mass transfer between air and desiccant.

The energy balance applied to both the humid air and the solid matrix gives:

$$
\dot{m}_{a}\left(I_{h a, i n(i, j)}-I_{h a, o u t(i, j)}\right)+\dot{m}_{m}\left(I_{w m, i n(i, j)}-I_{w m, o u t(i, j)}\right)+\dot{m}_{w(i, j)} \Delta I_{w e t(i, j)}=0
$$

where the wet solid matrix specific enthalpy is defined as:

$$
I_{w m}=\left(c_{p, m}+W c_{p, w}\right) T_{m}
$$

and the integral heat of wetting generated in the solid matrix:

$$
\Delta I_{w e t(i, j)}=\left(\Delta I_{a d s(i, j)}-\Delta I_{\operatorname{con}(i, j)}\right)
$$

The humid air specific enthalpy (Eq. (5)) uses liquid water at $0^{\circ} \mathrm{C}$ as reference state, and the same reference state is used for the wet solid matrix specific enthalpy (Eq. (10)) that covers the water sensible heat content only. Therefore, the first term on the LHS of Eq. (9) considers water condensation/evaporation and not adsorption/desorption on the desiccant surface. The second term accounts for desiccant sensible heat exchange and the third term accounts for the enthalpy difference between the adsorption/desorption and the condensation/evaporation heat. The third term may be viewed as a sorption correction term in the 
energy balance for the entire $\mathrm{CV}$, which corresponds to the integral heat of wetting as suggested in (Barlow, 1982).

Combining Eq. (4) and (9) results in the energy balance of the solid matrix:

$$
\dot{m}_{m}\left(I_{w m, i n(i, j)}-I_{w m, o u t(i, j)}\right)+\dot{Q}_{s e n s(i, j)}+\dot{m}_{w(i, j)} \Delta I_{a d s(i, j)}=0
$$

and shows that the latent heat exchanged by the solid matrix is directly proportional to the integral heat of adsorption.

\section{Heat and mass transfer}

The airflow regime in the channels is always laminar in the whole range of typical operating conditions. The Reynolds number is below 500 for air at $30^{\circ} \mathrm{C}$ and $50 \%$ relative humidity, and air velocities up to $5 \mathrm{~m} / \mathrm{s}$ with a channel hydraulic diameter of approximately $1.5 \mathrm{~mm}$.

The Nusselt number for fully developed laminar flow in a sinusoidal channel depends only on the channel dimensions as reported in (De Antonellis et al., 2010), and it is calculated as a function of the channel aspect ratio (see Fig. 1):

$$
N u_{F D}=1.1791 \cdot\left[1+2.7701 \frac{a}{b}-3.1901\left(\frac{a}{b}\right)^{2}+1.9975\left(\frac{a}{b}\right)^{3}-0.4966\left(\frac{a}{b}\right)^{4}\right]
$$

The local Nusselt number along a channel is calculated by taking the hydraulic and thermal boundary layer development into consideration (De Antonellis et al., 2010):

$$
N u_{(i, j)}=N u_{F D}+\frac{0.0841}{0.002907+\left[\left(D_{h} / x\right) \operatorname{Re}_{(i, j)} \operatorname{Pr}_{(i, j)}\right]^{-0.6504}}
$$

where $x[\mathrm{~m}]$ is the local position along the DW axis, set to zero at the channel entrance.

The heat and mass transfer analogy states that the Sherwood number can be calculated with the same correlation used for the Nusselt number by substituting the Prandtl number by the the Schmidt number. As the flow is always laminar in the channels, the Nusselt and Sherwood number are constant and equal for fully developed laminar flow as reported in Eq. (13). Using this approach and introducing the Lewis number, Le, gives (Mills, 2001): 


$$
\sigma_{(i, j)}=\frac{h_{(i, j)}}{c_{p, a} L e_{(i, j)}}
$$

where the Lewis number is defined by $\mathrm{Pr} / \mathrm{Sc}$. It means that when the heat transfer coefficient is known so is the mass transfer coefficient by Eq. 15. In addition, the model includes expressions for the adsorption isotherm and the heat of adsorption, which depend on the desiccant material as explained in the following.

\section{MODEL IMPLEMENTATION}

The model is implemented in the Professional version of Engineering Equation Solver (EES, 2014). The numerical method has been tested in the range of conditions reported in Table 1. The number of computational cells is limited because of EES maximum storage capacity for variables of 12000. In the current implementation, the solution procedure solves each computational cell in a subprogram, starting at the lower right most cell of Fig. 3, marching forward cell by cell first along the air flow direction and then in the desiccant flow direction. An outer iteration loop updates the desiccant temperature and moisture content at circumferential positions $360^{\circ}$ and $0^{\circ}$ until convergence. In this way, the size of the equation system to solve by EES is reduced so that the number of computational cells may be increased significantly. A central difference scheme (CDS) is adopted to approximate all variables onto the CV centers. The heat and mass transfer coefficients are calculated for each CV using an internal procedure. The number of axial and circumferential CVs can be varied for the whole wheel. The stop criteria used in the EES solver are listed in Table 2.

\section{RESULTS}

\section{CASE STUDY}

This section presents a model validation with experimental data from Tsutsui (2008) and is performed at various regeneration air inlet conditions, air flows, wheel lengths and rotational speeds. The model validation may also be viewed as a sensitivity analysis of the most important inputs to the model. First the influence of the grid refinement is analyzed before the validation with similar case setup as in Tsutsui (2008). 


\section{CASE SETUP}

The measurements reported in (Tsutsui, 2008) are obtained with thermocouples with a precision of $\pm 0.05^{\circ} \mathrm{C}$ for temperatures and dew point sensors with precision of $\pm 0.2^{\circ} \mathrm{C}$ for dew points. The dimensions of the sinusoidal channels are chosen to obtain a similar hydraulic diameter as in (Tsutsui, 2008), where a honeycomb structure was considered. The input dimensions are reported in Table 3.

The considered desiccant material is regular density (RD) silica gel, whose properties are reported in Table 4 (Barlow, 1982).

The RD silica gel adsorption isotherm is calculated neglecting the effect of temperature (Pesaran, 1980):

$$
\phi_{e q}=0.0078-0.0576 \cdot W+24.17 \cdot W^{2}-124.48 \cdot W^{3}+204.23 \cdot W^{4}
$$

According to Eq. (16) the maximum water content in the desiccant is approximately $40 \%$ of its dry mass.

The integral heat of adsorption of RD silica gel is expressed as a function of the latent heat of condensation and the water content in the desiccant (Brandemuehl, 1982):

$$
\Delta I_{a d s}=\Delta I_{c o n} \cdot\left(1+0.2843 \cdot e^{-10.28 \cdot W}\right)
$$

Eq. (16) and (17) are used for both adsorption and desorption, i.e. the two processes have the same characteristics and the only difference is the direction of heat and mass transfers.

For all simulations, the reference operational input values to the model are reported in Table 5.

\section{MODEL VERIFICATION}

The influence of the grid refinement is initially investigated for selecting the number of CVs to use for simulating the DW operation. The comparison between different grid refinements is carried out by comparing the air outlet temperature and moisture content at the $\mathrm{CV}$ faces (nodes). The required computational times (using a computer equipped with an Intel Core i7-3720 CPU and 8 GB RAM) and

process air outlet conditions obtained at the reference conditions from Table 5 with different grid refinements (number of circumferential CVs / number of axial CVs) are reported in Table 6. 
The results from Table 6 suggest that a model based on few CVs can be used to obtain a converged overall performance. Also a 1D model seems to be sufficient. More detailed results are is provided by the Mollier diagrams containing the air outlet and internal conditions along the DW circumferential direction. These diagrams are shown for three different grid refinements (200/1, 40/5 and 200/5) in Fig. 5.

The average air outlet conditions for the three grid refinements considered in Fig. 5 are practically the same, as reported in Table 5, but the air outlet conditions at different circumferential locations differ. Using more circumferential CVs (200/5) as in Fig. 5c allows for capturing the significant variation of air conditions at the beginning of both process and regeneration sections. This is important for e.g. optimizing the angle of an eventual purge section between the regeneration and process sections. The use of less circumferential CVs leads to local unphysical trends, as in Fig. 5b, where it is noticed that the air conditions fluctuate at the beginning of both process and regeneration sections. The trends are even exceeding the physical limits imposed by the specific inlet conditions with 2 iso-relative humidity lines and 2 iso-enthalpy lines (Goldsworthy and White, 2012). The cause of the unphysical conditions is addressed to be the use of the CDS for solving the model, which is known to provide unphysical results when too rapid variations and/or coarse grids are used (Patankar, 1981). However, the majority of computed conditions has a correct physical meaning providing correct average conditions. Using a 1D model with a fine circumferential grid refinement (200/1) as in Fig. 5a does not cause any unphysical behaviour but leads to an erroneous estimation of the air outlet conditions at the beginning of both sections. In fact, comparing Fig. 5a and 5c, the air outlet conditions with the 1D model are much closer to the physical limits in both process and regeneration sections.

The comparison of internal air temperature and moisture content distributions (at the CV centers) for the same grid refinements are shown in Fig. 6.

Fig. 6 show that decreasing the number of CVs to a $1 \mathrm{D}$ model allows to obtain the same property variations, but the steep changes at the beginning of both sections are not correctly captured. When more $\mathrm{CVs}$ are added in the axial direction, more information about variations of properties are also added. However, enough circumferential CVs have to be used for visualising the steep changes in the beginning of both sections correctly. Another extra information given by Fig. 6 is about the regeneration angle and/or the inlet regeneration air conditions (flow rate, temperature and humidity) necessary for regenerating the DW. 
It is observed, in both circumferential and axial directions in the end of the regeneration section, the air conditions do not change further, meaning that the air and the desiccant are close to equilibrium. The latter information is important for optimizing the DW operation. Variations of the regeneration angle lead to different Moisture Removal Capacity (MRC) and required regeneration airstream conditions to regenerate the desiccant material before entering the process side. (Chung and Lee, 2008) reported that the optimal regeneration angle maximizing the MRC decreases for increasing regeneration temperatures.

The desiccant temperature and water content distributions in the CV centers in the DW are also reported in Figure 7 for the grid refinement 200/5, confirming the last observation made on Fig.6. The sensible and latent heat flows exchanged by the air and their driving potentials are reported in Fig. 8.

Fig. $8 \mathrm{a}$ and $8 \mathrm{~b}$ show that the sensible and latent heat flows vary similarly, both circumferentially and axially. The highest flows are found closer to the inlet faces in the beginning of both process and regeneration sections, and moving forward along the circumference the highest heat flows become the nearest ones to the outlet faces of both sections. The heat flows in the regeneration section show peaks and then become null at different circumferential locations, which move further as the considered CV is closer to the outlet face. This is connected to what was already observed in Fig. 6e and 6f: the applied regeneration air conditions regenerate the wheel before the end of the regeneration section, while at the end of the process section it is still possible to dehumidify the air. Fig 8c and $8 \mathrm{~d}$ show that the sensible and latent heat flows vary in accordance with their driving potentials, i.e. the temperature difference between the air and the desiccant (see Eq. (6)) and the humidity ratio difference between the bulk of the air and the layer of air on the desiccant surface in equilibrium with it (see Eq. (7) and (8)) respectively. Fig. 8e and $8 \mathrm{f}$ show more in detail that the peaks are caused by different variations of the temperatures and humidity ratios between the air and the desiccant surface. In particular the conditions on the desiccant surface vary less smoothly than in the air, as they are driven by the considered adsorption isotherm (see Eq. (16)). The flow of heat of wetting is found to vary similarly to the flow of latent heat, as both are influenced by the flow of sorbed water, i.e. the humidity ratio difference between the air and the surface. However the flow of heat of wetting varies between 2 and $-1 \mathrm{~W}$, i.e. not influencing the energy balance in comparison to the sensible and latent heat flows, significantly. 


\section{MODEL VALIDATION}

The grid refinement $200 / 5$ is chosen for carrying out the model validation against experimental data from the literature (Tsutsui, 2008). This is done by a sensititvity analysis of some important inputs to the DW. Simulations are performed at various regeneration temperatures $T_{\text {reg }}$ (regeneration air inlet temperature), air face velocities, DW lengths, and wheel rotational speeds as shown in Fig. 9, 10 and 11. The wheel rotational speed is identified as the parameter influencing the computational time the most: for increasing wheel rotational speeds, i.e. mass flow rates of solid matrix in a $\mathrm{CV}$, the computational time increases.

Fig. 9 shows good agreement between the model and experimental data in terms of temperatures, while there are some differences in terms of humidity ratios, up to $1 \mathrm{~g} / \mathrm{kg}$ for $T_{r e g}=80^{\circ} \mathrm{C}$ and high wheel rotational speed, for which also temperatures differ approximately $4^{\circ} \mathrm{C}$. It is noticed that in all cases the model underestimates dehumidification in comparison to experimental data at low rotational speeds and overestimates it at high rotational speeds.

Fig. 10 also shows a better agreement between the model and the experimental data in terms of temperatures than humidity ratios, where the latter may differ up to $1.5 \mathrm{~g} / \mathrm{kg}$ for $u_{\text {face }}=1 \mathrm{~m} / \mathrm{s}$ at high rotational speeds. The largest discrepancies for the temperatures are observed at lower $u_{\text {face }}$. Again, dehumidification is underestimated by the model at low rotational speeds and overestimated at high rotational speeds.

Fig. 11 shows that the model provides the same trends as the experimental data for both temperatures and humidity ratios. The computed humidity ratios for DW lengths of 200 and $400 \mathrm{~mm}$ become almost equal at high rotational speeds. The largest differences between the computed values and experimental data are found for the longest DW at high rotational speeds, where the humidity ratio and temperature difference are $1.5 \mathrm{~g} / \mathrm{kg}$ and $11^{\circ} \mathrm{C}$, respectively. The air heating capacity is always underestimated to different extents depending on the rotational speed, however the difference between the computed temperatures and experimental data is almost constant for the whole range of rotational speeds. Also in this case dehumidification is generally underestimated at low rotational speeds and overestimated at high rotational speeds. 


\section{DISCUSSION}

The experiemental data from Tsutsui (2008) considers various regeneration air temperatures, air face velocities, DW lengths, and wheel rotational speeds, however, more experimental data are necessary to fully validate the model at varying air inlet conditions at both wheel sides and different regeneration angles. More detailed experiments have to be carried out to check and correct the discrepancies and further validate the model for all possible input variations.

The observed fluctuations from Fig. 5, 6 and 7, happening in connection to the use of low grid refinements, may have an influence on the results to some extent. Fluctuations can be eliminated by refining the grid, which increases the computational time. This is not desirable if the model should be implemented in complete system models.

The comparison with experimental data shows that the model reproduces the overall physical behavior of DWs. The model seems to underestimate the heating capacity on the process airstream, and to both underestimate and overestimate the dehumidification capacity depending on the wheel rotational speed. The understimations at low rotational speeds are smaller than the overestimations at high rotational speeds. A possible cause for the overestimations at high rotational speeds is that the model does not consider the solid-side mass diffusion resistance: diffusion phenomena in the desiccant pores (surface diffusion, Knudsen diffusion, multilayer adsorption, etc.) are already found to limit adsorption and desorption rates from previous studies (Pesaran and Mills, 1987), (Goldsworthy and White, 2012). The mass diffusion rate in the solid is influenced by the rotational speed: higher rotational speeds imply shorter contact times between air and desiccant, i.e. lower mass transfer rates. In other words, the steady state desiccant and air conditions get less close to equilibrium.

The solid-side mass transfer resistance should also be modelled for comparing different solid structures. As an example, increasing the density of the solid layer would increase the mass diffusion resistance while decreasing the conductive heat resistance, implying a trade-off between the heat and mass diffusive rates.

This missing phenomenon should be investigated by including the solid-side mass transfer resistance in adjunction with the solid-side heat transfer resistance. 
The computational effort to solve the model is low: few seconds are usually necessary for solving the model and no more than 10 seconds are needed even for the operating conditions most far from the operating point used for setting the guess values in EES. This makes the model particularly suitable for complete HVAC system simulations and optimizations.

The actual version of the model differs from the models presented in (Tsutsui, 2008) and (Harshe et al., 2005), because the convective heat and mass transfer coefficients are calculated for each control volume and not kept constant, hence entrance effects are taken into account. In both (Tsutsui, 2008) and (Harshe et al., 2005) mass transfer in the solid is not implemented. In (Harshe et al., 2005) it is proposed to fit experimental data by means of constant tuning parameters for Nusselt and Sherwood numbers, which cannot precisely describe phenomena varying with operational conditions (e.g. solid-side mass diffusion).

\title{
CONCLUSIONS
}

A steady state 2D model of desiccant wheels has been built and validated against experimental data from the literature. The model reproduced the same trends shown by experimental data from the literature as important parameters were varied. Some underestimation and overestimation of the performances still occurred. Possible causes are (1) the lack of other experimental data for this study and (2) the absence of mass diffusion resistance in the solid. The difference between the experimental data and the model results was found less than $8^{\circ} \mathrm{C}$ for the process air outlet temperatures and less than $12 \%$ in the humitiy ratio. The time to reach a solution of the model depended on the grid refinement. For all simulations the solution time was less than 1 minute, and for most grid refinements the solution time was less than 10 seconds. The low computational effort required by the model makes it particularly suitable for complete system simulations, where computational times can be discriminating. Moreover, the flexibility of the model in terms of inputs allows for optimization of desiccant wheels as well as entire systems.

\section{NOMENCLATURE}

\author{
Symbols \\ A apparent desiccant area $\left(\mathrm{m}^{2}\right)$ \\ a channel height (m) \\ b channel width $(\mathrm{m})$ \\ c channel wall thickness (m) \\ $\mathrm{c}_{\mathrm{p}} \quad$ specific heat capacity $(\mathrm{J} / \mathrm{kgK})$
}




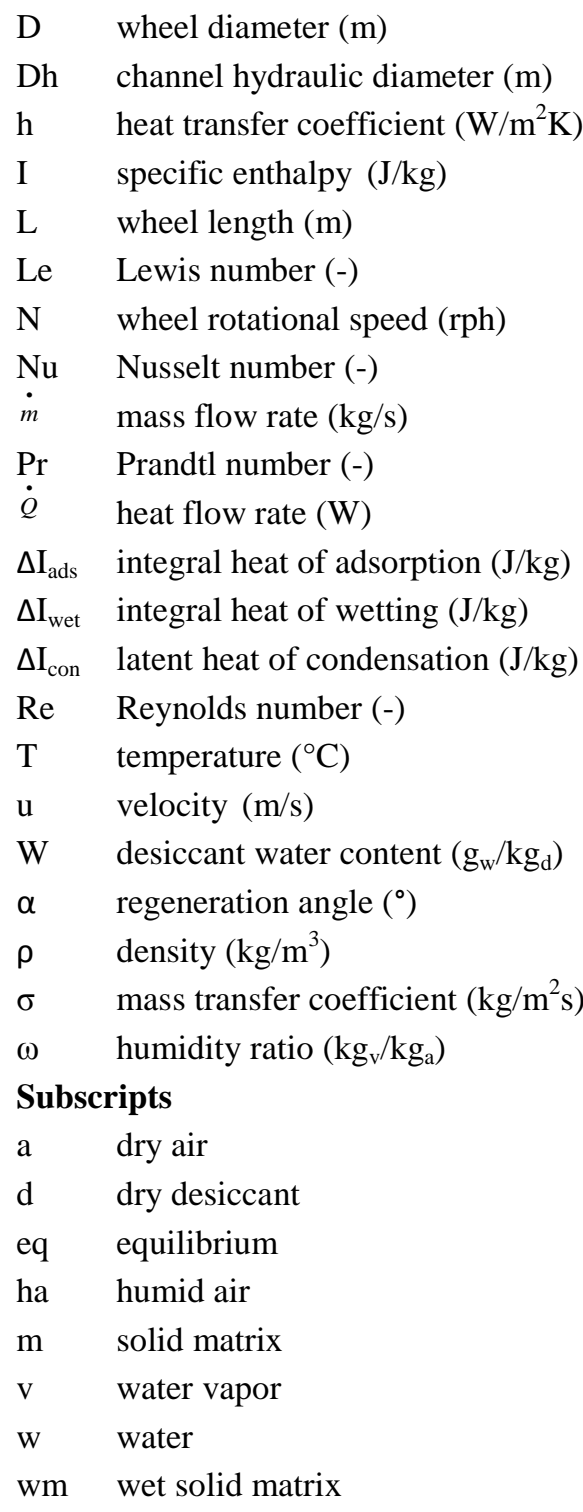

\section{REFERENCES}

Barlow, R.S., 1982, Analysis of the Adsorption Process and of Desiccant Cooling Systems: A Pseudosteady-state Model for Coupled Heat and Mass Transfer. Solar Energy Research Institute.

Brandemuehl, M.J., 1982, Analysis of Heat and Mass Regenerators with Time Varying or Spatially Nonuniform Inlet Conditions, PhD Thesis, Department of Mechanical Engineering, University of Wisconsin.

Chung, J.D., Lee, D.Y., 2009, Effect of desiccant isotherm on the performance of desiccant wheel, International Journal of Refrigeration, 32, 4: 720-726.

De Antonellis, S., Joppolo, C.M. and Molinaroli, L., 2010, Simulation, performance analysis and optimization of desiccant wheels, Energy and Buildings, 42, 9: 1386-1393.

EES: Engineering Equation Solver, F-Chart Software : Engineering Software. [online] Fchart.com. Available at: http://www.fchart.com/ees/ [Accessed 31 May 2014].

Ge, T.S., Li, Y., Wang, R.Z. and Dai, Y.J., 2008, A review of the mathematical models for predicting rotary desiccant wheel. Renewable \& Sustainable Energy Reviews, 12, 6: 1485-1528. 
Goldsworthy, M., White, S.D., 2014, The Performance of Desiccant Wheels for Desiccant AirConditioning, In: Nóbrega, C.E.L., Brum, N.C.L., Desiccant-Assisted Cooling, Springer London: 109141.

Goldsworthy, M., White, S.D., 2012, Limiting performance mechanisms in desiccant wheel dehumidification. Applied Thermal Engineering, 44: 21-28.

Harshe, Y., Utikar, R., Ranade, V. and Pahwa, D., 2005, Modeling of rotary desiccant wheel, Chemical Engineering\& technology, 28, 12: 1473-1479.

La, D., Dai, Y.J., Li, Y., Wang, R.Z. and GE, T.S., 2010, Technical development of rotary desiccant dehumidification and air conditioning: A review. Renewable \& Sustainable Energy Reviews, 14, 1: 130-147.

Mills, A.F., 2001, Mass Transfer. Prentice Hall PTR.

Patankar, Suhas V., 1981, Numerical Heat Transfer and Fluid Flow.

Pesaran, A.A., 1980, Air Dehumidification in Packed Silica Gel Beds, M.S. Thesis, School of Engineering and Applied Science, University of California Los Angeles.

Pesaran, A.A., Mills, A.F., 1987, Moisture transport in silica gel packed beds-I.Theoretical study. International Journal of Heat and Mass Transfer, 30, 6: 1037-1049.

Sattler, K., Feindt, H. J.,1995, Thermal separation processes : principles and design. VCH.

Tsutsui, K., 2008, Effect of design and operating conditions on performance of desiccant wheels. IIR 2008 HVAC energy efficiency best practice conference, Melbourne.

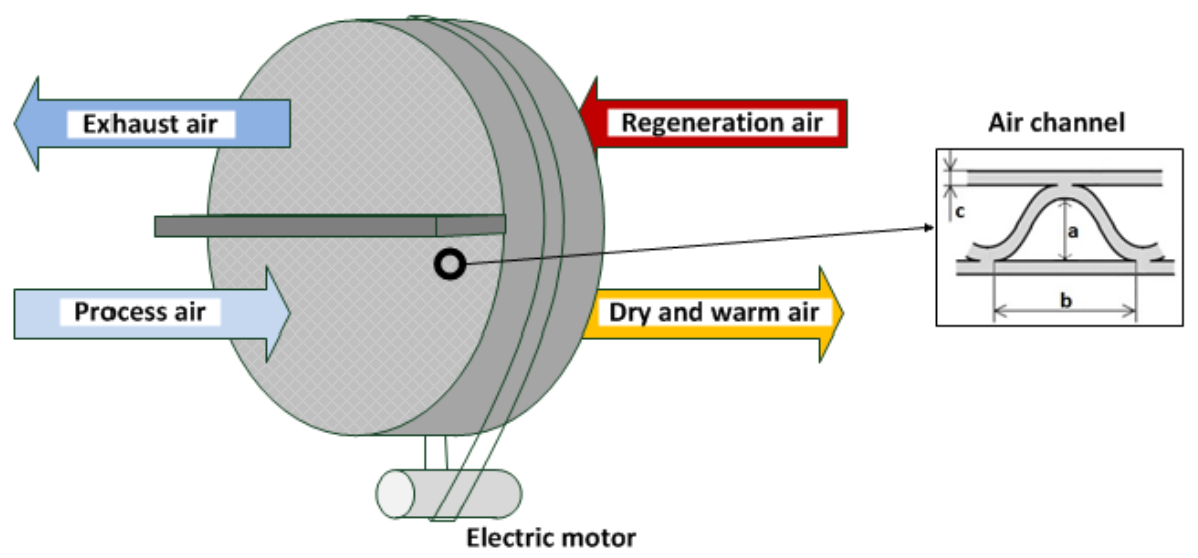

Figure 1. Desiccant wheel sketch and detailed front view of a simusoidal channel 

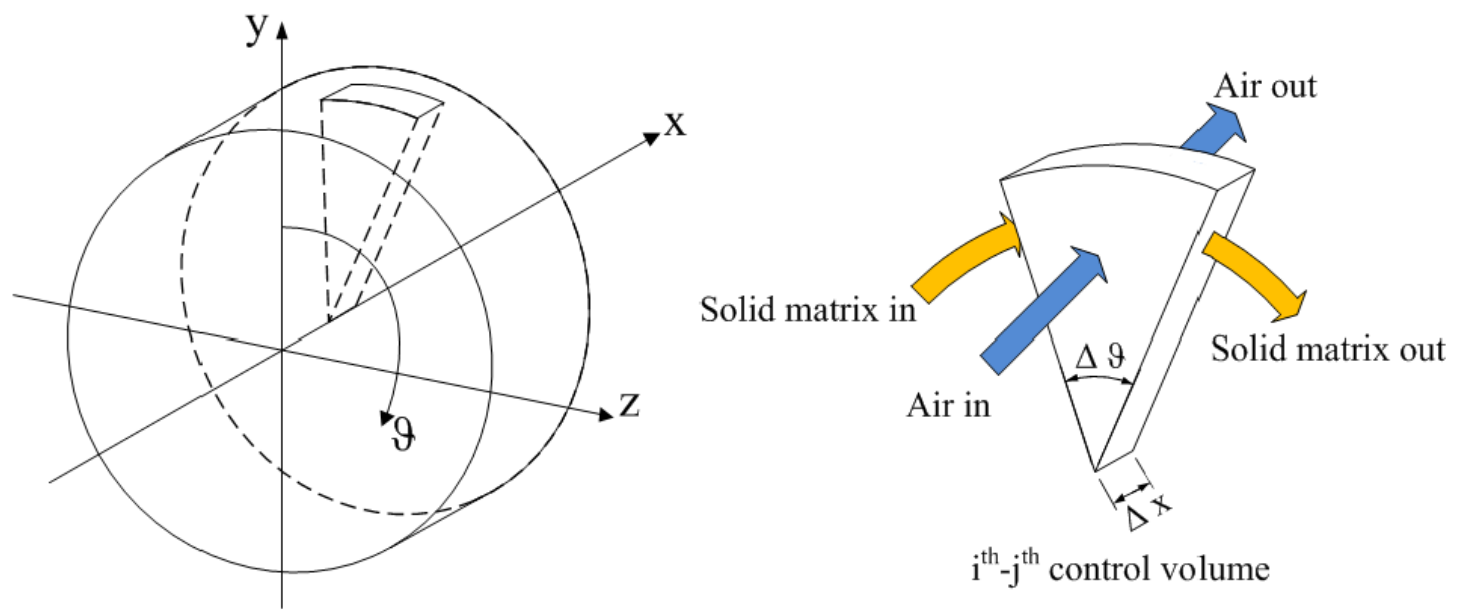

$\mathrm{i}^{\text {th }}-\mathrm{j}^{\text {th }}$ control volume

Figure 2. 2D Control volume discretization approach
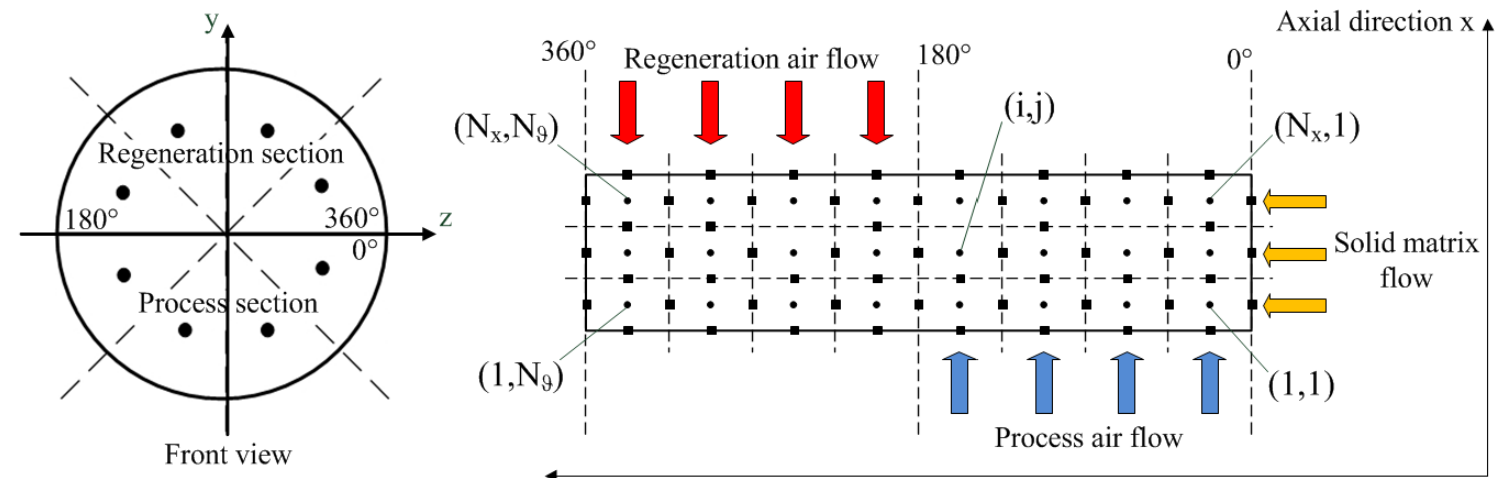

Circumferential direction $\vartheta$

Figure 3. $2 \mathrm{DDW}$ computational grid with $180^{\circ}$ regeneration angle 

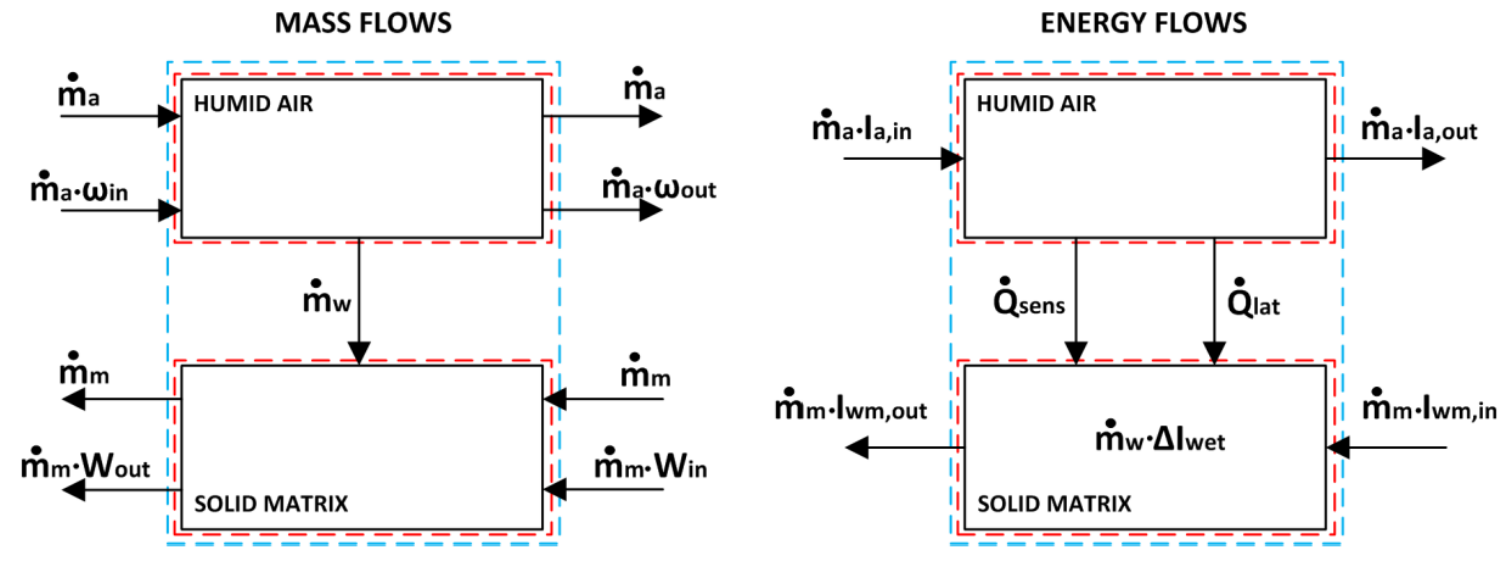

Figure 4. Mass and energy flows between the humid air and the solid matrix in a generic $C V$
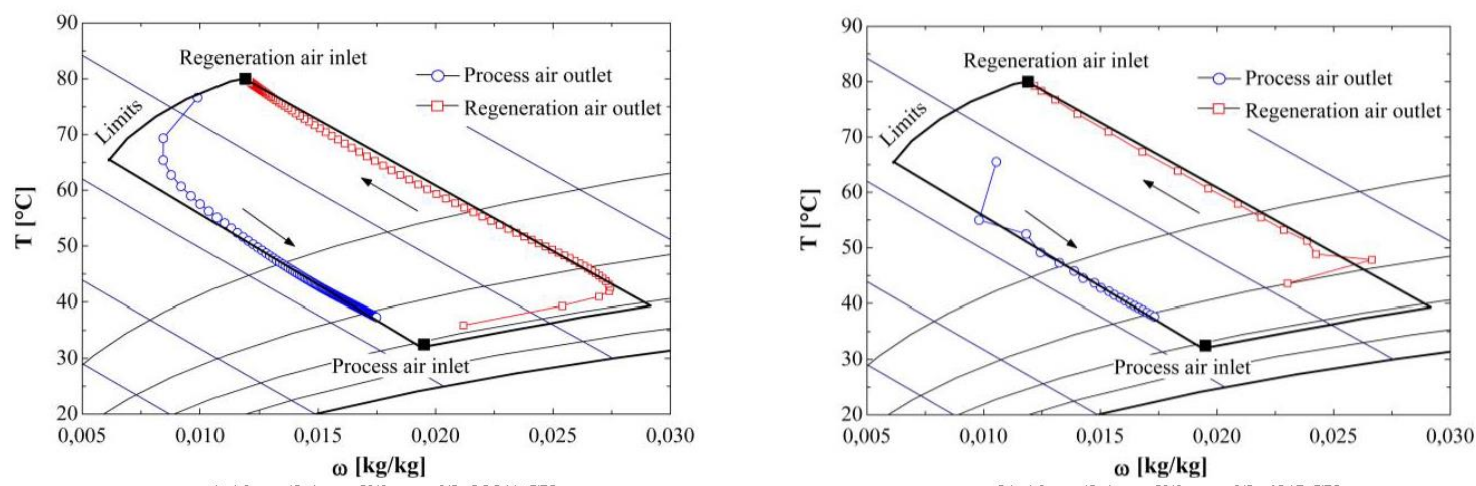

a) Air outlet conditions with $200 / 1 \mathrm{CVs}$

b) Air outlet conditions with $40 / 5 \mathrm{CVs}$

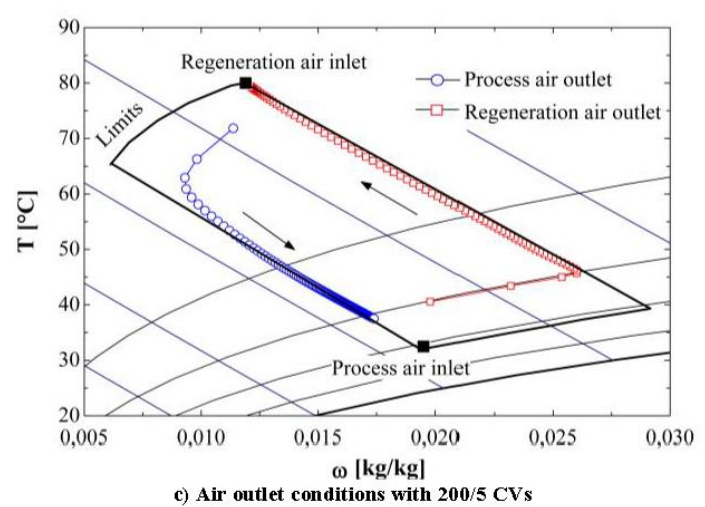

Figure 5. Air outlet conditions along the $D W$ circumferential direction with different grid refinements at the reference conditions 


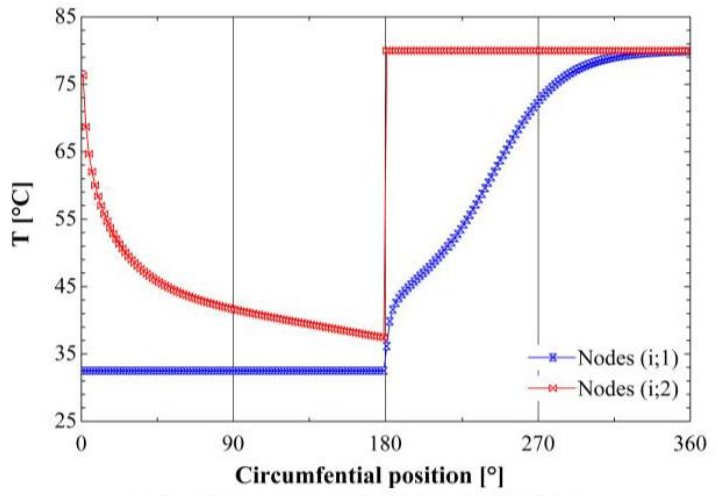

a) Air temperature distribution with grid 200/1

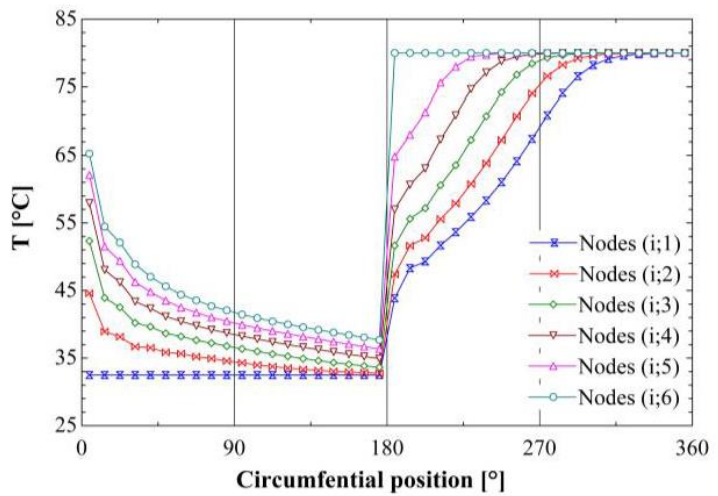

c) Air temperature distribution with grid 40/5

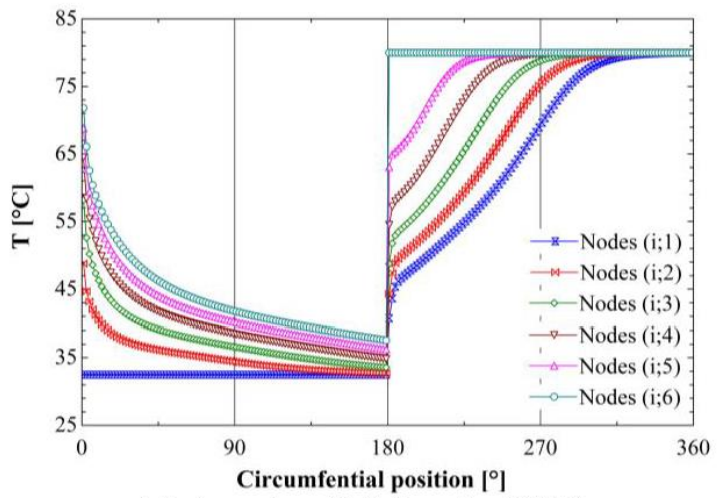

e) Air temperature distribution with grid 200/5

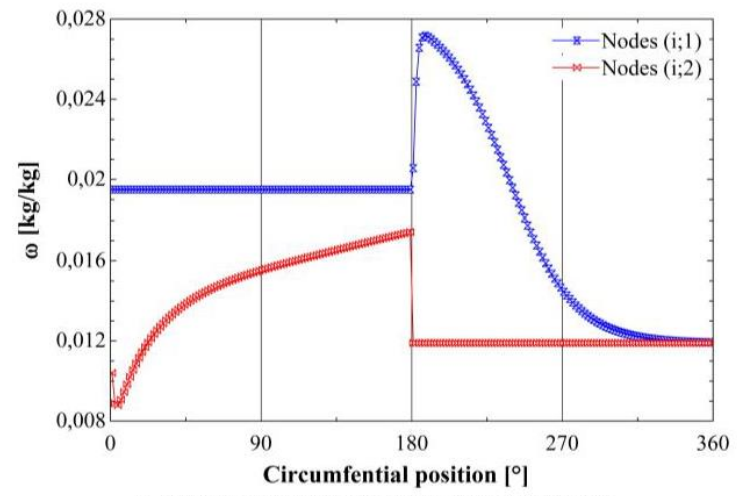

b) Air humidity ratio distribution with grid 200/1

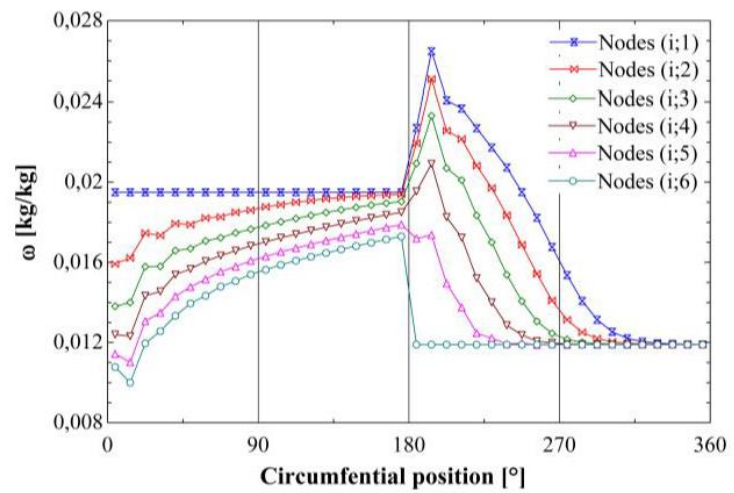

d) Air humidity ratio distribution with grid 40/5

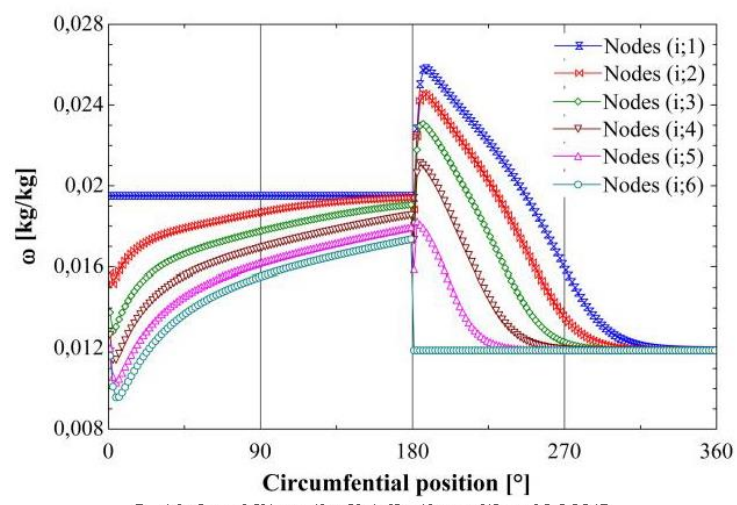

f) Air humidity ratio distribution with grid 200/5

Figure 6. Variation of air conditions in the $C V$ centers in the $D W$ for different grid refinements 

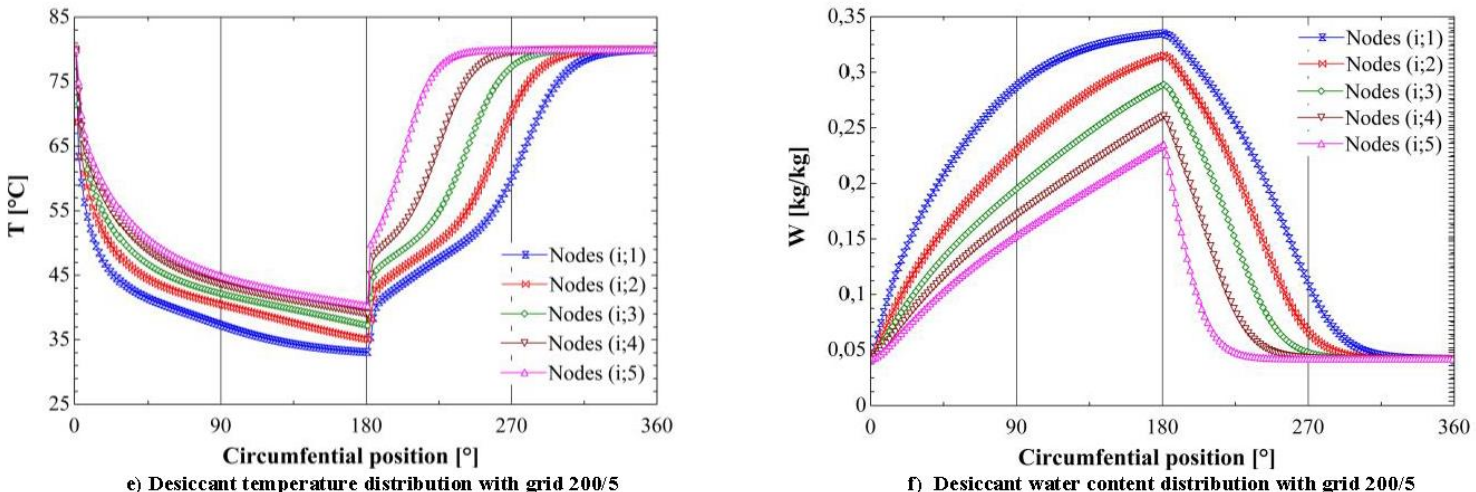

Figure 7. Variation of desiccant conditions in the $C V$ centers in the $D W$ 

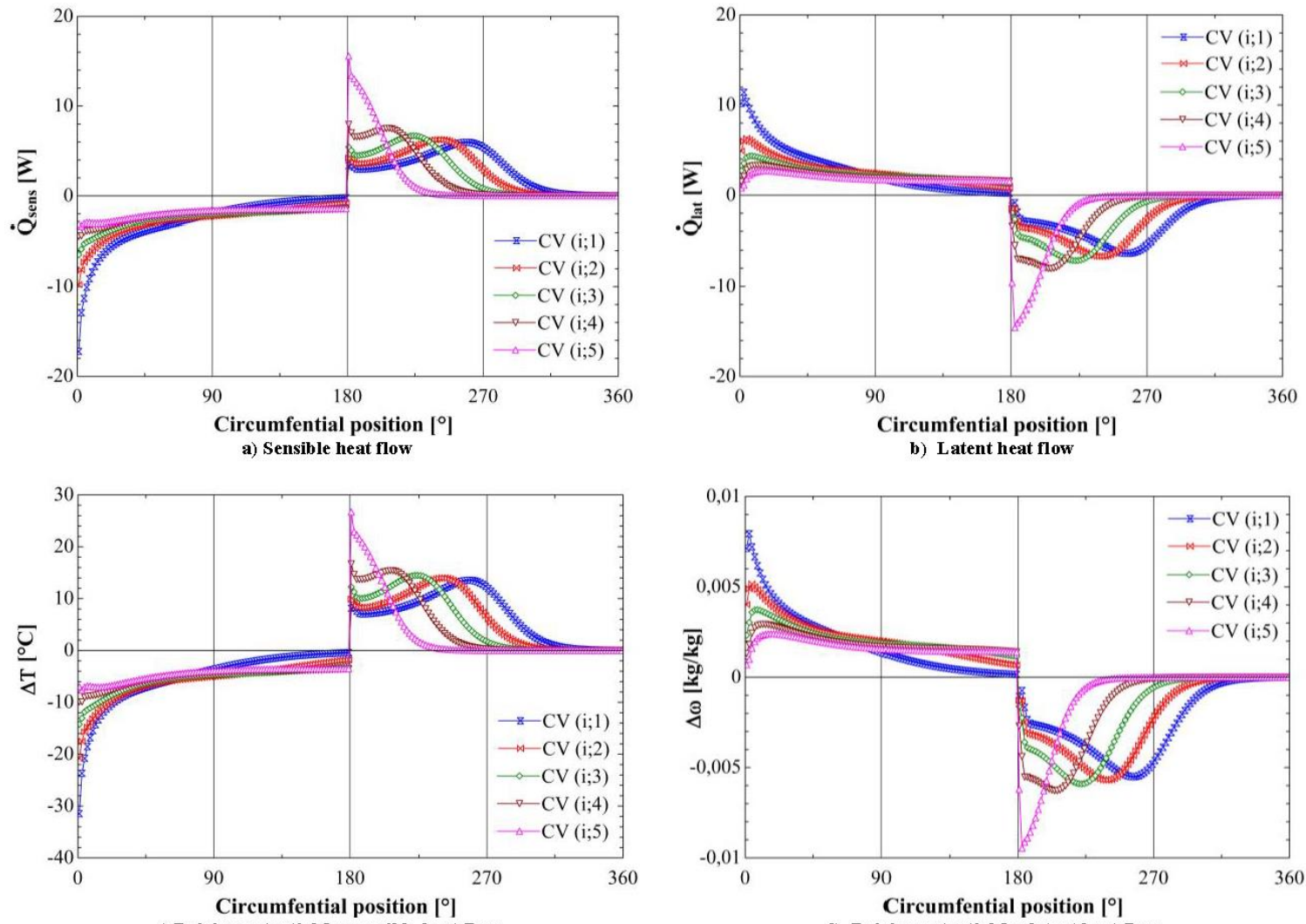

c) Driving potential for sensible heat flow
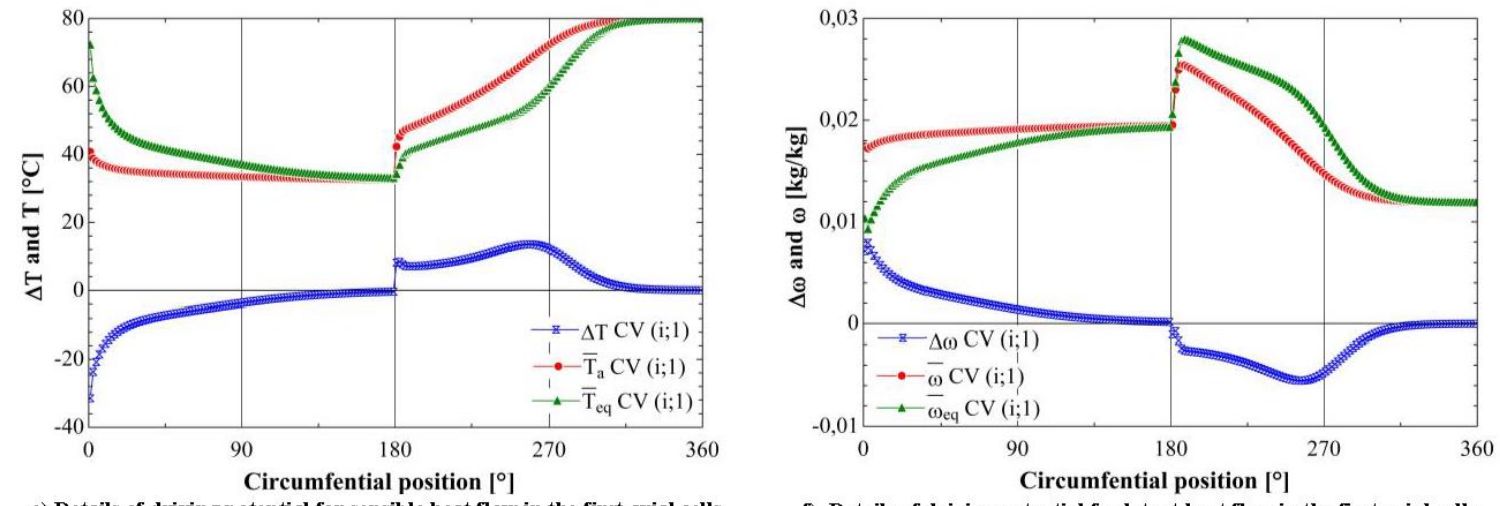

e) Details of driving potential for sensible heat flow in the first axial cells

f) Details of driving potential for latent heat flow in the first axial cells

Figure 8. Analysis of the sensible and latent heat flows exchanged by the air and driving potentials 

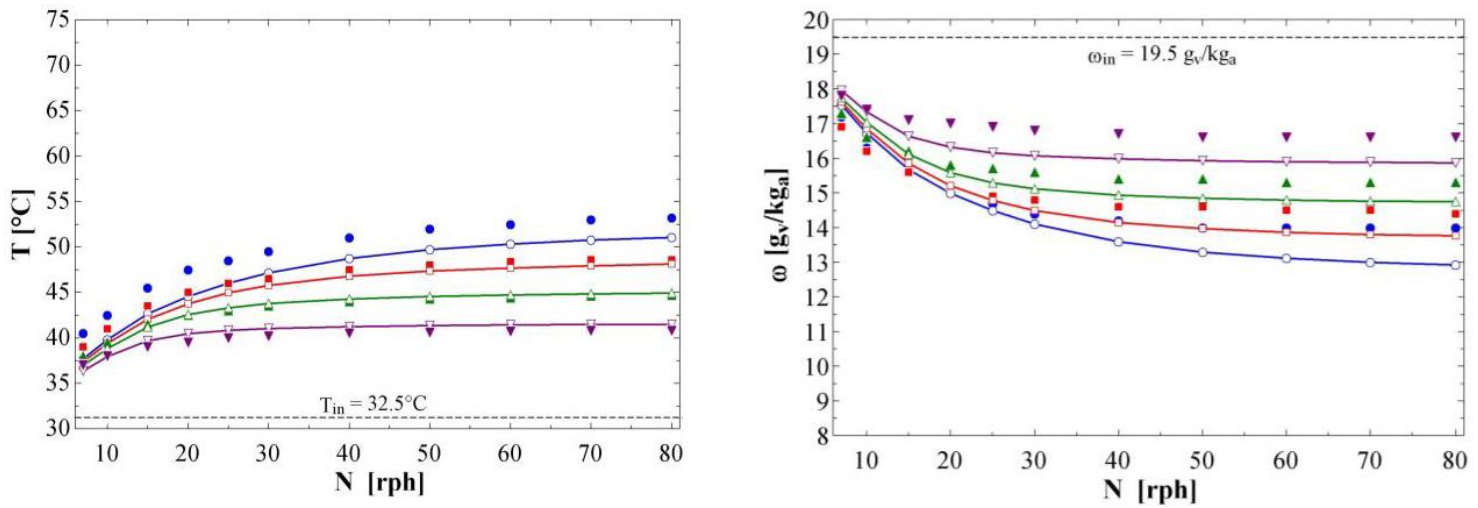

- $\mathrm{T}_{\mathrm{reg}}=80^{\circ} \mathrm{C}$ (literature) - $\mathrm{T}_{\mathrm{reg}}=70^{\circ} \mathrm{C}$ (literature)

$\Delta \mathrm{T}_{\text {reg }}=60^{\circ} \mathrm{C}$ (literature) $\quad \nabla \mathrm{T}_{\mathrm{reg}}=50^{\circ} \mathrm{C}$ (literature)

$\longrightarrow \mathrm{T}_{\text {reg }}=80^{\circ} \mathrm{C}$ (model) $\longrightarrow \mathrm{T}_{\text {reg }}=70^{\circ} \mathrm{C}$ (model)

$\longrightarrow \mathrm{T}_{\text {reg }}=60^{\circ} \mathrm{C}($ model $) \longrightarrow \mathrm{T}_{\text {reg }}=50^{\circ} \mathrm{C}($ model $)$

Figure 9. Process air outlet conditions for varying $T_{\text {reg }}$ and $N$
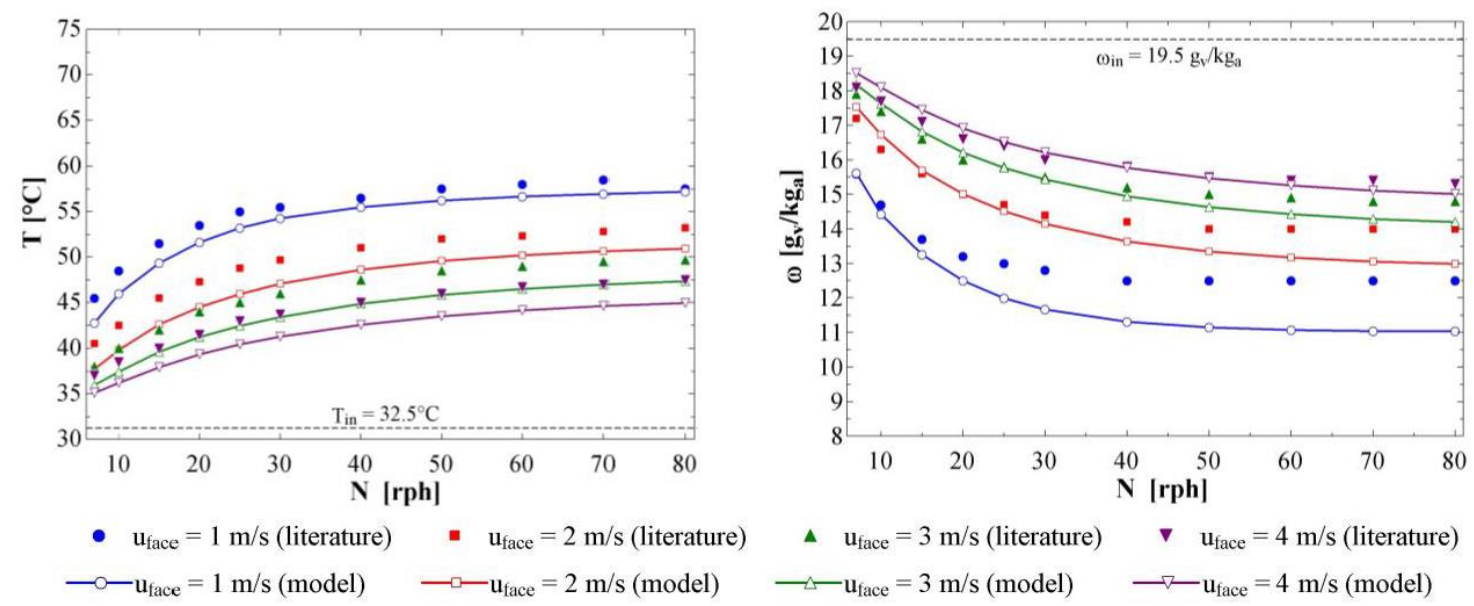

Figure 10. Process air outlet conditions for varying $u_{f a c e}$ and $N$ 


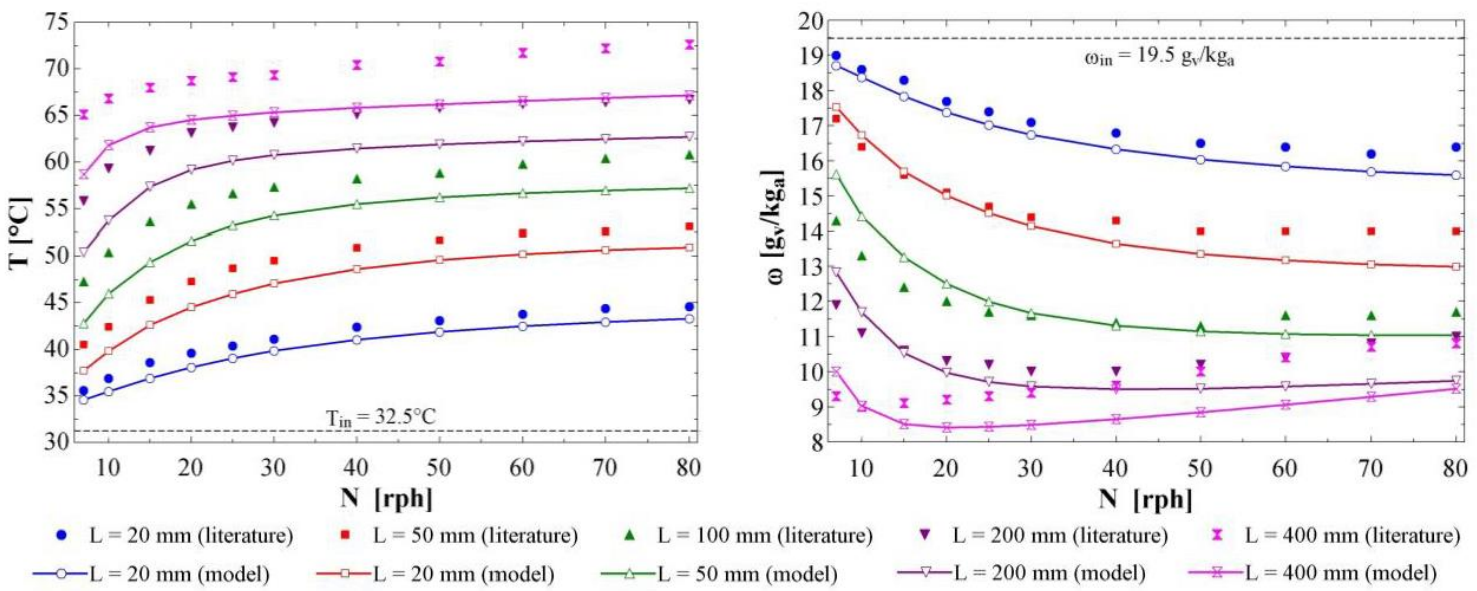

Figure 11. Process air outlet conditions for varying $L$ and $N$

\begin{tabular}{|c|c|}
\hline Table 1: Range of parameter values used for testing the DW model \\
\hline Parameter & Min/Max values \\
\hline Process side air inlet temperature $\left[{ }^{\circ} \mathrm{C}\right]$ & $15-40$ \\
\hline Regeneration temperature $\left[{ }^{\circ} \mathrm{C}\right]$ & $50-90$ \\
\hline Wheel rotational speed $[\mathrm{rph}]$ & $9-20$ \\
\hline Regeneration angle $\left[{ }^{\circ}\right]$ & $5-80$ \\
\hline Wheel diameter $[\mathrm{mm}]$ & $90-180$ \\
\hline Wheel length $[\mathrm{mm}]$ & $400-2000$ \\
\hline & $20-400$ \\
\hline
\end{tabular}

\begin{tabular}{|c|c|}
\hline \multicolumn{2}{|c|}{ Table 2: Stop criteria in EES solver } \\
\hline Criteria & Value \\
\hline Maximum number of iterations & 250 \\
\hline Relative residuals & $1 \mathrm{E}-06$ \\
\hline Change in variables & $1 \mathrm{E}-09$ \\
\hline Elapsed time [s] & 40 \\
\hline Outer loop tolerance & $1 \mathrm{E}-04$ \\
\hline
\end{tabular}

\begin{tabular}{|c|c|}
\hline \multicolumn{2}{|c|}{ Table 3: Reference DW characteristics } \\
\hline Parameter & Value \\
\hline DW diameter & $350 \mathrm{~mm}$ \\
\hline DW length & $50 \mathrm{~mm}$ \\
\hline Channel hydraulic diameter & $15.4 \mathrm{~mm}$ \\
\hline Channel height & $1.9 \mathrm{~mm}$ \\
\hline Channel width & $3.8 \mathrm{~mm}$ \\
\hline Channel wall thickness & $0.2 \mathrm{~mm}$ \\
\hline Regeneration angle & $180^{\circ}$ \\
\hline
\end{tabular}




\section{Table 4: Desiccant material properties}

Parameter

Silica gel density

Silica gel specific heat capacity

Value

$800 \mathrm{~kg} / \mathrm{m}^{3}$

$921 \mathrm{~J} /(\mathrm{kgK})$

Table 5: Reference operational input values for simulations

\begin{tabular}{|c|c|}
\hline \multicolumn{2}{|c|}{ Table 5: Reference operational input values for simulations } \\
\hline Parameter & Value \\
\hline Process air inlet temperature & $19.5 \mathrm{~g} / \mathrm{kg}$ \\
\hline Process air inlet humidity ratio & $80^{\circ} \mathrm{C}$ \\
\hline Regeneration air inlet temperature & $11.9 \mathrm{~g} / \mathrm{kg}$ \\
\hline Regeneration air inlet humidity ratio & $2 \mathrm{~m} / \mathrm{s}$ \\
\hline Process air face velocity & 1 \\
\hline Ratio of process and regeneration air volume flow rates & $20 \mathrm{rph}$ \\
\hline Wheel rotational speed & \\
\hline
\end{tabular}

Table 6: Comparison of results with different grid refinements

\begin{tabular}{|c|c|c|c|}
\hline \multicolumn{4}{|c|}{ Table 6: Comparison of results with different grid refinements } \\
\hline Grid refinement & Computational time [s] & $\mathbf{T}_{\text {out }}\left[{ }^{\circ} \mathbf{C}\right]$ & $\mathbf{\omega}_{\text {out }}\left[\mathbf{g}_{\mathbf{v}} / \mathbf{k g}_{\mathbf{a}}\right]$ \\
\hline $40 / 1$ & 1 & 44.13 & 14.82 \\
\hline $200 / 1$ & 3 & 44.12 & 14.82 \\
\hline $40 / 5$ & 4 & 44.16 & 14.82 \\
\hline $200 / 5$ & 23 & 44.14 & 14.82 \\
\hline $40 / 10$ & 8 & 44.17 & 14.81 \\
\hline $200 / 10$ & 50 & 44.16 & 14.82 \\
\hline
\end{tabular}

